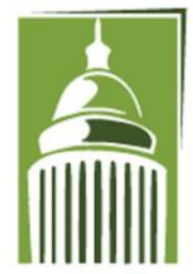

ARF
Global Proceedings Repository

American Research Foundation

ISSN 2476-017X

Available online at http://proceedings.sriweb.org

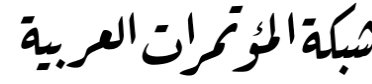

http://arab.kmshare.net/

The 10th International Scientific Conference

Under the Title

"Geophysical, Social, Human and Natural Challenges in a Changing Environment"

$$
\begin{aligned}
& \text { المؤتمر العلمي الدولي العاشر } \\
& \text { تحت عنوان "التحديات الجيوفيزيائية والاجتماعية والانسانية والطبيعية في بيئة متغيرة" } \\
& 25 \text { - } 26 \text { يوليو - تموز } 2019 \text { - اسطنبول-تركيا }
\end{aligned}
$$

\title{
Estimation of Alkaline Phosphatase Enzymes Level in the Femoral Transverse Fractures Healing in Rabbits
}

\author{
Humam H. Nazht ${ }^{\text {, }}$, Raffal A. Omar ${ }^{\text {a }}$, Muna R. A. Al Dahhan ${ }^{\text {, }}$, Rania \\ Khedr Khaleefa ${ }^{b}$,Sumaya Mohammed Kareem ${ }^{\text {b }}$, Zyad Maher Manual ${ }^{\text {, }}$, \\ Zaid Hussein Theiab ${ }^{b}$. \\ ${ }^{a}$ Surgery and obstetric department /college of veterinary medicine/University of Baghdad \\ /Iraq. \\ ${ }^{\mathrm{b}}$ veterinary medicine students /fifth class/university of Baghdad/Iraq \\ Humam_Nazhat@yahoo.com
}

\begin{abstract}
:
This project was designed to estimate alkaline phosphatase (ALP) enzymes level during fractures healing in rabbits fourteen adult male rabbits were employed to induce transverse fractures in the femoral bone, and fixed with intramedullary pining. The evaluation was done by daily clinical observation, weekly radiography, histopathological examination, and weekly serum ALP enzymes measurment. The clinical observation revealed local inflammatory signs, loss appetite and difficult to walk two days p. o. then re-use the limb gradually next week's with normal physiological activity, the radiographic findings revealed new bone formation that visible at the end of $2^{\text {nd }}$ week $\mathrm{p}$. o. which increase in volume and density next weeks until the boney bridge formation at the end of $4^{\text {rd }}$ week, the radiological union created at the end of $6^{\text {th }}$ week p. o. , the histopathological examination showed osteoid deposition and immature trabecular bone formation with highly differentiated osteoblast cells at the end of the $2^{\text {nd }}$ week $\mathrm{p}$. o. which converted to mature and lamellar bone formation at the end of the $4^{\text {th }}$ week , while at the end of the $8^{\text {th }}$ and $10^{\text {th }}$ wk p. o. increase lamellar bone formation, with less of the osteoblast cells ,the serial mean serum ALP enzyme measurement
\end{abstract}




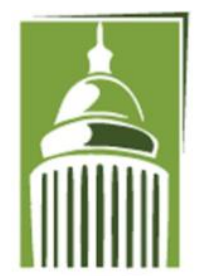
ARF

\section{Global Proceedings Repository}

American Research Foundation

ISSN 2476-017X

Available online at http://proceedings.sriweb.org

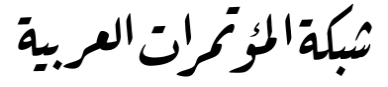

http://arab.kmshare.net/

first week prior to the operation was $41.15 \pm 3.57 \mathrm{C}$, which increased to $99.50 \pm 0.89 \mathrm{~b}$ end of $1^{\text {st }}$ week, and $96.00 \pm 1.48 \mathrm{~b}$ end of $2^{\text {nd }}$ week, reach $108.00 \pm 7.30 \mathrm{~b}$ end of $3^{\text {rd }}$ week , and $213.00 \pm 0.68$ a end of $4^{\text {th }}$ week, $192.00 \pm 23.55$ a end of $6^{\text {th }}$ week, $96.10 \pm 1.45 \mathrm{~b}$ end of $8^{\text {th }}$ week, $96.10 \pm 18.07 \mathrm{~b}$ end of $10^{\text {th }}$ week . of the peak of ALP revealed significant increase at the end of $4^{\text {th }}$ and $6^{\text {th }}$ week p. o. at $\mathrm{P}<0.05$, compare with the other weeks, and the mean value of all week significant at $\mathrm{P}<0.05$ compare with the first week prior to operation .The conclusion serum ALP enzyme is a bio marker indictors of fractures healing stages, and have a positive correlation with the osteoblast cells activity and bone formation.

Key words: Transverse fracture of femoral bone, ALP enzyme level, radiological union, lamellar bone formation. ALP biomarker.

\section{Introduction:}

Fractures are a medical condition associated with a broken of bone continuity, result from impact force, stress, or from a certain medical condition that weaken the bones, as in osteoporosis, bone cancer, or imperfect angiogenesis in pathological fracture (Marshall and Browner, 2012).

Many developments of internal fixation methods animal fractures like intramedullary pins, stainless steel wires, bones plates with screws, interlocking nails, in attempt to stabilization, minimized tissue trauma and promote biologic osteosynthesis (Stiftler, 2004).

(Nazht,1992) used PGF2 alpha in promoting fractures healing in dogs ,or using PGE2 in promote bone resorption in the remodeling phase of rabbits long bones fractures ( Nazht,2000), the same author applied low level laser therapy (LLLT) to promote fracture healing in the distal third of the radius bones in doge (Nazht et al ., 2016 ; Nazht and Hamed ,2017 ). Or evaluate the effect of LLLT on the osteoblast cells in healing defect of the mandible bones of rabbits (Nazht ,2013), or study the effect of the LLLT on the xeno -bone implantation in femoral fractures in rabbits (Nazht et al .,2018 a) or evaluate the positive effect of the LLLT on the chronic defect in rabbits tibial bone ( Nazht et al.,2018 b) or used xeno sheep bony implantation for fill and treat femoral defect ( Nazht et al ., 2018 c).

Fractures healing process can be detected clinically by estimation serial serum ALP level and can be indicators for osteoblastic and cellular activity and differentiation. ALP increase 2 days post stimulation with increases of osteoblastic cells up to 14 days ( Komnenan et al ., 2005), and could be used in predicting fractures in delayed / nonunion of simple diaphyseal fractures ( Nishizawa et al .,2013;Singh Ajai,2013).

While (Chiba, 2001) mention that the serum ALP is highe 10 to 14 days after fracture in fibrous tissue cells adjacent to newly bone formation, and in osteoblasts cells on the surface of newly trabecular bone formation, but not in the hematoma during the inflammation phase of fracture healing,while (Muljacic et al ., 2010) refer that the Volume of Callus formation correlates with BALP enzymes which determined radiographically in fracture healing processing at the end of the $2^{\text {nd }}$ and $4^{\text {th }}$ weeks . 


\section{Global Proceedings Repository \\ American Research Foundation}

ISSN 2476-017X

Available online at http://proceedings.sriweb.org

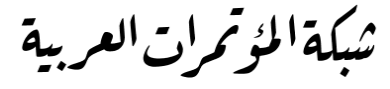

http://arab.kmshare.net/

(Singh Ajai et al., 2013) observed significant increase serum ALP levels in the normal bone union group as compared with the delayed healing group. Komnenou et al. in (2005) refer that the serum ALP activity was determined throughout the healing process of long bone diaphyseal fractures in their research on dogs and human.

(Marcos et al., 2008) refer that fractures healing processing can be evaluated by histomorohometric study which shows intense cellularity, and large amount of woven bone with a small amount of lamellar bone, At two weeks there was a decrease in woven bone with increase in lamellar bone, while at four weeks there was a decrease cellularity and the lamellar bone exceeded the quantity of woven bone.

The mechanism of ALP enzyme is by increase the local concentration of inorganic phosphate (a mineralization promoter), and decrease extracellular concentration of pyrophosphate (an inhibitor of mineral formation), it located outside plasma membrane, and matrix vesicles membrane (Ellis Kathleen, 2007). ALP contains many growth factors, (Zimmermann et al. 2005), and it is an important component in hard tissue formation, highly expressed in mineralized tissue cells (Cristina et al., 2015).

The aim of this project was to estimate the serial serum ALP enzymes level during fracture healing processing and its correlations with osteoblast cells activities and new bone formation in induced transverse femoral fracture in rabbits.

\section{Materials and methods:}

Fourteen adult local breed rabbits were employed to induced a transverse fracture in the mid shift in the femoral bone with highly aseptic technique under general anesthesia by intramuscular administration of both, $17 \mathrm{mg} / \mathrm{kg}$ B.W.of $2 \%$ xylazine hydrochloride and $35 \mathrm{mg} / \mathrm{kg}$ B.W of $10 \%$ ketamine hydrochloride respectively. The two fracture fragments were fixed internally by intramedullary pin

\section{Surgical operation:}

Prepare the thigh region, by clipping, shaving, wash with tape water and soap .then disinfect the area by $70 \%$ alcohol , $4 \mathrm{~cm}$ length skin incisions was made laterally , and the subcutaneous tissues was dissected ,the fascia lata was incised ,the femoral muscles were bluntly dissected all around the femoral diaphysis, the periostium was incised and exposed the femoral bone by inserting two scalpels below the femoral bone. Complete transverse fracture was induced by electrical saw with dipping sterile normal saline to prevent the thermal necrosis (Fig $1 \mathrm{~A}$ and B), the two bone fragments were fixed with intramedullary pins ,apply local antibiotics powder, the femoral muscles and the fascia lata were closed by simple continuous suture pattern using $2 / 0$ absorbable suture materials, the skin closed by simple interrupted suture pattern by using $2 / 0$ non absorbable suture materials

\section{Post operative care:}

1. Daily checking operative site from complication( swelling bleeding dehiscence). 


\section{Global Proceedings Repository \\ American Research Foundation}

ISSN 2476-017X

Available online at http://proceedings.sriweb.org

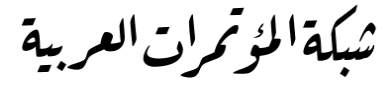

http://arab.kmshare.net/

ARF

2. Systemic antibiotics by intramuscular injection lincomycine for 3 days p. o.

3. Remove the suture materials 8 days p. o.

4. Removed internal pins after radiological union at the end of the $6^{\text {th }}$ week's p. o.

\section{Post operative examination:}

1. Daily clinical observation for limb gate, lameness ,.normal physiological functions

2. Weekly radiography at the end of $2^{\text {nd }}, 4^{\text {th }}, 6^{\text {th }}, 8^{\text {th }}$, and $10^{\text {th }}$ wks $p$. o.(by lateral recumbence(medio-lateral view) at dosage of $\mathrm{Kv}=48-53 / \mathrm{Mas}=2 \cdot 20-4 / \mathrm{F} . \mathrm{F} . \mathrm{D}=30 \mathrm{~cm}$ ).

3. Histopathological examination at the end of, $2^{\text {nd }}, 4^{\text {th }}, 8^{\text {th }}$, and $10^{\text {th }}$ wk sp. o. (two rabbits for each week, which euthanized by high dosage of general anesthesia).

4. Serum ALP level measurement at 0 times prior to induced transverse fracture then at the end of the $1^{\text {st }}$ wk., $2^{\text {nd }} w k ., 3$ rd wk. $4^{\text {th }}$ wk., $6^{\text {th }}$ wk., $8^{\text {th }}$ wk. , and $10^{\text {th }} w \mathrm{wk}$ p. o. . (Collecting $3-5 \mathrm{ml}$ blood from the heart and the serum ALP enzymes measured in the private clinical pathology lab).

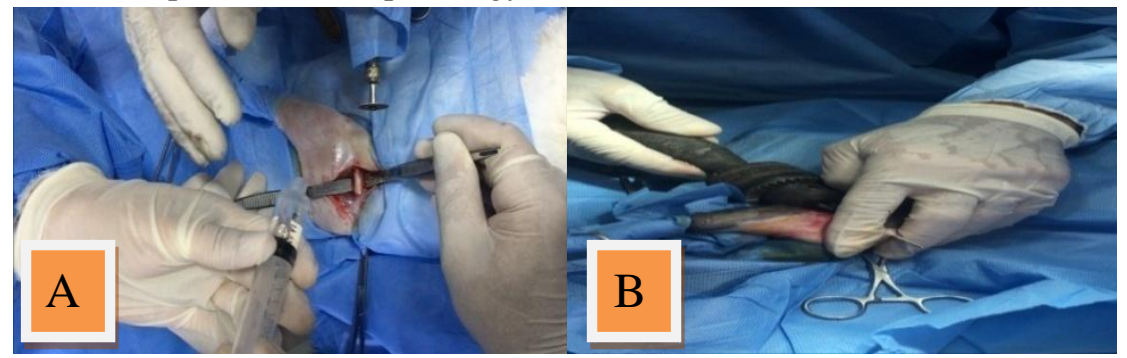

Figure 1 stages of the surgical operation, A. Exposed femoral bone to induced transverse fracture by electrical saw and cooling by normal saline, B. intramedullary pinning.

\section{Results:}

\section{The clinical observation :}

- Swelling at the surgical site immediately p. o. with body depression, refused to eat, difficult to move, and hold the effected limb during standing.

- The animals retained to eat with normal physiological behaviors 2-3 days p. o.

- The local inflammatory signs disappear 3-5 days p. o.

- The surgical incision healed satisfactory without complications 7-10 day's p. o.

- The animals support the affected limb during stopping at the end of the first week and hold it during walking, in the second week the animals use the affected limb during walking but hold it during running .while At the end of the third week and beginning of the fourth week p. o. the animals normally use the affected limb in walking and running.

- At the end of the sixth week remove the intramedullary pin, and the animal normally used the limb in walking running and can bear the weight.

\section{The radiographic finding:}

- $\quad$ End of second week p. o. 


\section{Global Proceedings Repository \\ American Research Foundation}

ISSN 2476-017X

Available online at http://proceedings.sriweb.org

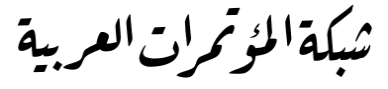

http://arab.kmshare.net/

The periosteal reaction was visible which revealed new bone formation characterized by low bone density that started from the proximal and distal fractures segments toward the fracture site (Fig. 2).the fractures segments well fixed with proper alignment by the intramedullary pinning which filled about $60-70 \%$ of the marrow canal

- End of the fourth week p. o.

Increase volume and density of callus formation, but still not cove the fracture line, the fracture line disappear with sclerotic area, the fracture fragments well alignment, fixed and stable by the intramedullary pin (Fig. 3).

- $\quad$ End of sixth week p. o.

Radiological union created, the bony bridge formation covered the two segments with increase of bone density and stopped in formation bony callus, sclerotic area at the site of fracture line, widening of cortex (Fig. 4).

- $\quad$ End of $8^{\text {th }}$ wk two months p. o.

Two weeks after removing the intramedullary pinning show well alignment of the two femoral fragments with increase density of the new bone formation, widening the cortex around the fracture line (Fig. 5).

- The end of $10^{\text {th }}$ wk p. o.

Remodeling stages achieved by stooping new bone formation, increase density, smooth border, sclerotic area at the fracture line with increase the cortical bone (Fig. 6).

3. The histopathological examination:

- The end of the $2^{\text {nd }}$ wk p. o.

Increase in the differentiated osteoblast cells that lining the inner border of thin wall of immature trabecular bone formation with, large empty cavities filled with vasclurized fibrous connective tissues (Fig. 7).

- The end of the $4^{\text {th }}$ wk. p. o.

less of immature bone formation which converted to the lamellar bone with a lot of osteoblast cells but less than in $t$ the second week p. o (Fig. 8).

- The end of the $8^{\text {th }}$ wk. p. o.

Lamellar bone formation with compact bone formation little of the osteoblast cells, less in the cavity inside the new bone formation (Fig. 9).

- The end of the $10^{\text {th }}$ wk p. o.

Lamellar bone formation with haversain systems, blood vessels in the Haversian canal with the osteocyts cells inside the lacuna (Fig. 10).

\section{The serum ALP enzymes level measurements:}

The weekly statistical analysis of mean value of ALP enzymes done by SAS (2012). The serial mean value of ALP enzyme significantly increased at $(\mathrm{P}<0.05)$ from the end of $1^{\text {st }}$ week until end of $10^{\text {th }}$ week p. o, compare with the $1^{\text {st }}$ week prior to the operation (Fig. 11). The 


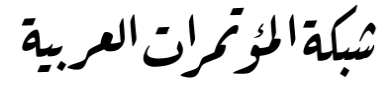

http://arab.kmshare.net/

ARF

Available online at http://proceedings.sriweb.org

peak level was detected in the $4^{\text {th }}$ week then the level was decreased in the $6^{\text {th }}$ week, but still it significant compare with others week (Fig. 12).at end of $8^{\text {th }}$ and $10^{\text {th }}$ weeks more decrease but above the mean value in the first weak prior to operation.

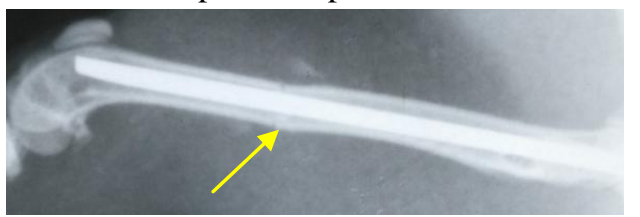

Figure 2. Radiographic image end of second week p. o. periosteal reaction well appears yellow arrow visible fracture line, with smooth end fractures fragments

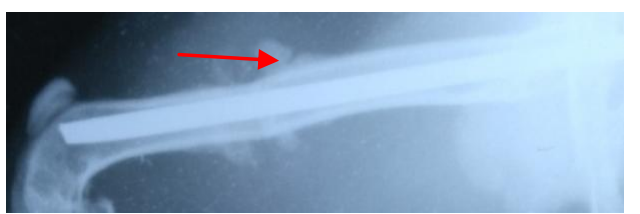

Figure 3. Radiographic image end of fourth week p. o. increase in volume and density of the new bone formation red arrow, the fracture line disappear with high sclerotic area.

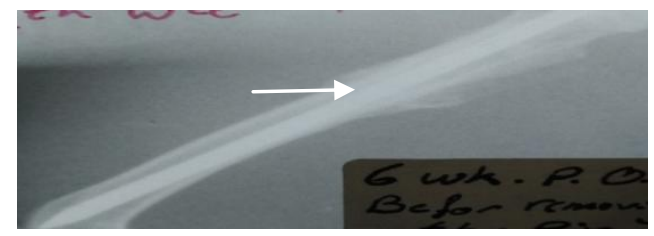

Figure 4 . Radiographic image end of sixth week p. o. radiological union white arrow represents bony bridge formation; with hard callus formation

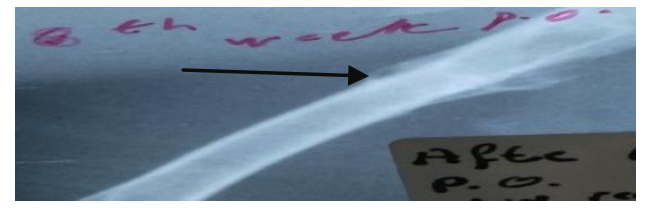

Figure 5. End of the eight week p. o. two week after remove the intramedullary pins, represents sclerotic area at the fracture line incorporation of the cortex black arrow with continuous of the remodeling phase.

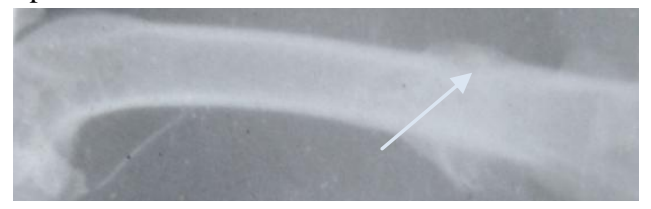

Figure 6. Radiographic image end of tenth week p. o. increase of cortex at the fracture site gray arrow. 


\section{Global Proceedings Repository \\ American Research Foundation}

ISSN 2476-017X

Available online at http://proceedings.sriweb.org

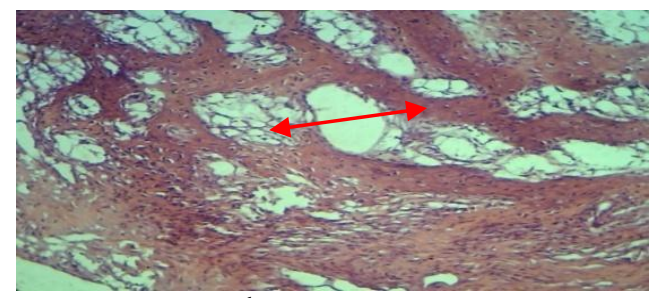

Figure 7. Histopaphological section end of $2^{\text {nd }}$ week p. o. immature trabecular bone formation red double head arrow, ostoblasts cells lining at the bone surface $(\mathrm{H} \& \mathrm{E} \times 10)$

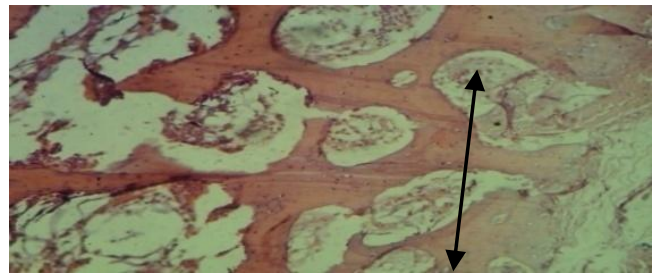

Figure 8. Histopathological section end of $4^{\text {th }}$ week p. o. trabecular new bone formation with thick wall converted to lamellar bone, lining with osteoblast double head black arrow $(\mathrm{H} \& \mathrm{E} \times 10)$.

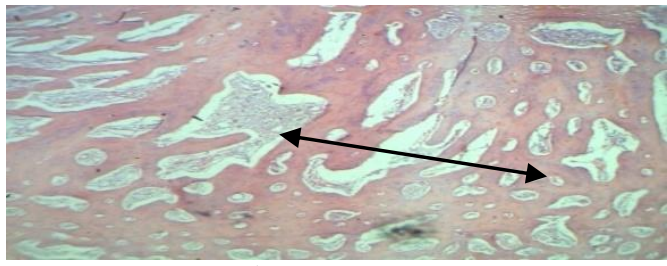

Figure 9. Histopathological section end of $8^{\text {th }}$ week p. o. the fracture line filled with the new trabecular bone formation, lamellar bone formation, with cavity filled with vascular connective tissues black double head arrow $(\mathrm{H} \& \mathrm{E} \times 10)$.

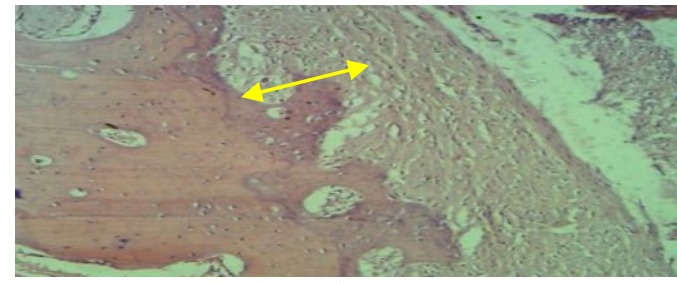

Figure 10. Histopathological section end of $10^{\text {th }}$ week p. o. represents lamellar bone formation .

Enzyme level during healing process

\begin{tabular}{|c|c|c|c|c|c|c|c|c|}
\hline & \multicolumn{8}{|c|}{ Time / week } \\
\hline$-k$ & $\mathbf{0}$ & End Wk1 & End Wk2 & End Wk3 & End Wk4 & End Wk6 & End Wk8 & End Wk10 \\
\hline & \multicolumn{8}{|c|}{ Mean } \\
\hline & $41.15 \pm 3.57 \mathrm{c}$ & $99.50 \pm 0.89 b$ & $96.00 \pm 1.48 \mathrm{~b}$ & $108.00 \pm 7.30 \mathrm{~b}$ & $213.00 \pm 0.68 \mathrm{a}$ & $192.00 \pm 23.55 a$ & $96.10 \pm 1.45 b$ & $96.10 \pm 18.07 b$ \\
\hline
\end{tabular}

Figure 11 table of the mean value of ALP during healing processing 


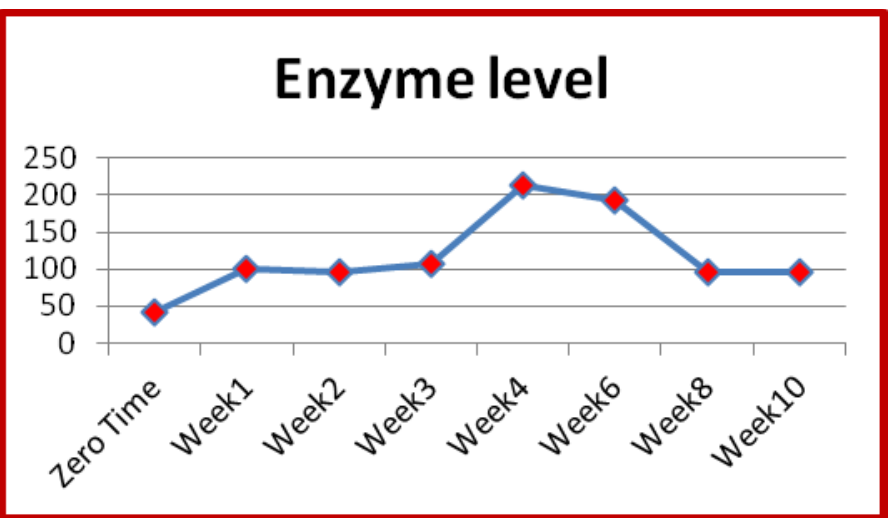

Figure 12 graphic of weekly mean disturbution of ALP enzyems during fractures healing .

\section{Discussion:}

The clinical observation first day's p. o. quickly retained to normal two to three days p. o, and the animals re-used the limb gradually next days and weeks, these note agree with (Lastayo et al .,2003) that The operated rabbits hold the affected limb during movement within two days p. o. then they began to use it in movement and support the weight $7^{\text {th }}$ day $p$. o, in which lameness disappear gradually in stable fractures

Femoral fracture that fixed by intramedullary pinning well fixed, stable, easy and popular to use agree with ( Christodoulou et al., 2005) that internal fixation has $97 \%$ rate of using in femur and tibia. And healing by indirect (secondary) fractures healing by callus formation (Gerstenfeld et al., 2006) The healing processing is enhanced by micro motion and weight-bearing. (Pape et al., 2002; Perren, 2002; Green et al., 2005).

The callus formation visible radiographically at the end of the $2^{\text {nd }}$ week $p . o$. that increase in volume and become denser next weeks and reach the peak at the end of $4^{\text {th }}$ week, and at $6^{\text {th }}$ week p. o. radiological union created these conducted with (Gerstenfeld et al., 2006) that callus formation progresses and becomes more solid and mechanically rigid with cartilage calcification and replaced by woven bone.

(Chiba,2001) refer ALP is elevated 10 to 14 days after fracture due to proliferation and activation of osteoblasts cells on the of newly formed trabecular bone surface. that lead to osteoid formation and enhance mineralization.these also agree with Muljacic and his group in 2010 that the volume of callus correlates with level of BALP and reflected the increase on defect density radio graphically using image $\mathrm{j}$ at the end of 2 and 4 weeks and at computerized tomography at the end of 4thweek. 


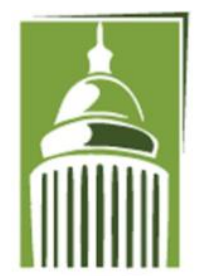

ARF

\section{Global Proceedings Repository \\ American Research Foundation}

ISSN 2476-017X

Available online at http://proceedings.sriweb.org

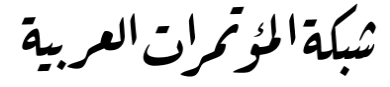

http://arab.kmshare.net/

The serial increase of serum ALP enzymes during fractures healing compare with 0 time, were combined with osteoblasts cells activity with new bone formation radiographically and histopathologically, agree with (Kurdy, 2000; Komnenou et al., 2005; Singh Ajai et al., 2013) that serum ALP activity was determined throughout the healing process. and was significantly increased at the end of 2 weeks in tibial fracture up to 10 th week after the trauma.

The results of histopathological examination were conducted with (Marcos et al., 2008) that in the first week of fracture healing intense cellularity and woven bone formation, At four weeks decrease in woven bone and increase in lamellar bone and decrease of cellularity, and at the end of healing processes the lamellar bone exceeded the quantity of woven bone with less of the osteoblast cells.

The elevation of the ALP level at the $3^{\text {rd }}$ week p. o. that contain many growth factors lead to osteoid deposition and mineralization and convert the immature trabecular bone to the mature ones that determined radiographically by increase in density and volume of bony callus around the fracture line, agree with (Zimmermann et al., 2005).

The peak of ALP enzymes level at the $4^{\text {th }}$ week p. o. achieved histopathologically by converted immature trabecular bone to mature trabecular bone formation with heavy of osteoblast cells, and radiographiclly achived by increase volume and density of callus formation with disappear of fracture line ,these conducted with (Singh Ajai et al. ,2013) That serial increase serum ALP is a bio marker indicators for fractures healing .

At the end of $6^{\text {th }}$ week p. o. ALP decline companied with lamellar bone formation, decrease in the osteoblast cells, achieved radiographically by bony bridge formation, disappear fracture line, stopped of callus formation and starting of the remodeling phase . these agree with ( Komnenan et al ., 2005) serum ALP responsible for both, bone matrix formation and mineralization, with positive correlation progression of fracture healing processing

At the end of 8 th and $10^{\text {th }}$ week p. o. ALP declines but still above the 0 time level and achieved histopathologically by lamellar bone formation with less osteoblast cells, and radiographically which shown sclerotic area at the fracture line with starting the remodeling phase. These agree with (Komnenan et al ., 2005). That during fractures healing stages the weekly elevation of serum ALP enzymes has a positive correlation osteoblast cells activation and differentiate with new bone formation.

\section{Conclusions:}

Serum ALP enzyme is bio markers indictors of fractures healing stages, and has a positive correlation with the osteoblast cells activity and new bone formation.

\section{References:}

- $\quad$ Chiba, S.; Okada, K.; Lee, K.; Segre, GV.; and Neer, RM. (2001) .Molecular analysis of defect healing in rat diaphyseal bone. J Vet Med Sci. ;63(6):603-608. 


\section{Global Proceedings Repository \\ American Research Foundation}

ISSN 2476-017X

Available online at http://proceedings.sriweb.org

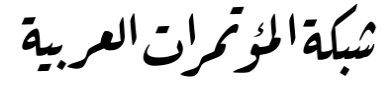

http://arab.kmshare.net/

- Christodoulou, A.;Terzidis Ploumis,A.;Metsovitisi, s.; Koukoulidiss. A.; and Toptsis, C. (2005).Supracondylar femoral fracture in elderly patients treated with the dynamic condylar screw and the retrograde intramedullary nail:a comparative study of the two methods. Arch orthop Trauma Surg; 125:73-9

- Cristina, P. Sousa; Isabel, R. Dias; Mónica, Lopez-Peña; José, A. Camassa;Paulo, J. Lourenço; Fernando M. Judas;Manuela E. Gomes; and Rui 1. Reis (2015). Bone turnover markers for early detection of fracture healing disturbances: A review of the scientific literature An Acad Bras Cienc (2015) 87 (2)An Acad Bras Cienc 87 (2).

- Ellis, E. Golub ; and Kathleen Boesze - Battaglia (2007).The role of alkaline phosphatase in mineralization Curr Opin Orthop Lippincott Williams \& Wilkins 18:444-448.

- Gerstenfeld, LC. ; Alkhiary, YM.; and Krall, EA. et al. (2006).Three-dimensional reconstruction of fracture callus morphogenesis. Journal of Histochemistry \& Cytochemistry.; 54(11):1215-28.

- Green, E.; Lubahn, JD.; and Evans, J. (2005).Risk factors, treatment, and outcomes associated with nonunion of the midshaft humerus fracture. Journal of Surgical Orthopaedic Advances.; 14(2):64-72.

- .Komnenou,A.; Karayannopoulou, M.; Polizopoulou ,ZS.;Constantinidis, TC.; and Dessiris, A. (2005). Correlation of serum alkaline phosphatase activity with the healing process of long bone fractures in dogs. Vet Clin Pathol 34: 35-38

- Kurdy, NM. (2000).Serology of abnormal fracture healing :the role of PIIINp,PICP, and BsALP.J Orthop Trauma.;14(1):48-53

- Lastayo , P. C. ;Winters, K. M. ; and Hardy , M.(2003).Fracture healing:bone healing, fracture management and current concepts related to the hand . j. hand ther. 16 (2): 81-93.

- Marcos, A. Matos;Francisco, P. Araújo ;andFabio B Paixão(2008).Histomorphometr ic evaluation of bone healing in rabbit fibular osteotomy model without fixation Journal of Orthopaedic Surgery and Research 3:4

- Marshall,T. ;Browner,B.D.(2012) [1st. Pub. 1956] "Chapter20: Emergency care of musculoskeletal injuries”.In Courtney M. Towsend Jr. Sabiston textbook of surgery: the biological basis of modern surgical practice. Elsevier. Pp. 480_520.

- Muljacic, A.;Guberina, RP.;Turcic, J. ;Zivkovic, O.;Guberina, M.;and Klaic B. (2010).The changes of bone specific alkaline phosphates associated with callus formation and rate of bone healing .Crotica. Chemica. Acta.;83:315-321.

- Nazht, Humam H. ; Omara, Raffal A. ; AlDahhana, Muna R.A. ; and Ahmed, Hatem k .( 2018 a) .effect of low level laser therapy on the sheep ribs xeno graft in the treatment of rabbits long bone fractures, The Ninth International Scientific Academic Conference 17-18 July Istanbul/turkey .volum 3.

- $\quad$ Nazht , Humam , H. ; Al-khazrajii, Sinan,A.N.;and Omar, Raffal,A.( 2018 b).effect of low level leaser therapy on the chronic defect of tibial bones in rabbits, Basrah Journal of Veterinary Research,Vol.17,No.3.Proceeding of 6th International Scientific Conference,College of Veterinary Medicine University of Basrah,Iraq 


\section{Global Proceedings Repository \\ American Research Foundation}

ISSN 2476-017X

Available online at http://proceedings.sriweb.org

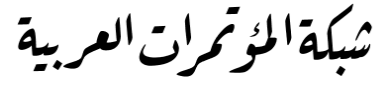

http://arab.kmshare.net/

- Nazht, H.H.; Omar, RA.;and Ahmed, HK.( 2018 c). Sheep rib xenograft femoral bone implant in rabbits Online Journal of Veterinary Research 22 (4), 290-299.

- Nazht, H. H. ; and Khaliad, F. R. ( 1992).The effects of prostaglandin (PGF2a) on fracture healing in long bones: Radiological, clinical and histological studies ( M.Sc. thesis) Veterinary Medicine College - Baghdad University, Baghdad - Iraq

- Nazht, HH. ; and Jawad, NMA. ( 2000).Effects of prostaglandin E2 on bone resorption in the remodeling phase of the femoral bone fractures in rabbits ( Ph.D thesis) Veterinary Medicine College - Baghdad University - Baghdad - Iraq

- Nazht, Humam H. and Hamed, Natheers Ahmed. (2017). Radiological Effect of the Low Level Laser Therapy on Fracture Healing in the Distal Third of Dogs, Elixir International Journal Hormones and Signaling Elixir Hor. \& Sig. 107 42209-42211

- Nazht, H. H. (2013). Histopathological study of the effect of the laser on the osteoblast cells during mandible defect in Rabbits ,Al-Anbar J.Vet. Sci.,Vol.: 6 No.

- Nazht, Humam H.; Faleh, Inam Badr ; and Hamed, Natheer Ahmed (2016). histopathological study of the distal third fractures of radius in dogs, treated with LLLT, Bas.J.Vet.Res.Vol.15,No.1, ISI Impact Factor:3.461.

- Nishizawa, Y.; Ohta, H.; Miura, M. et al. (2013).Guidelines for the use of bone metabolic markers in the diagnosis and treatment of osteoporosis (2012 edition). J Bone Miner Metab.; 31(1):1-15.

- Pape, HC.; Giannoudis, PV. Grimme, K. et al. (2002).Effects of intramedullary femoral fracture fixation: what is the impact of experimental studies in regards to the clinical knowledge? Shock.; 18(4):291-300.

- Perren, SM. (2002).Evolution of the internal fixation of long bone fractures. The scientific basis of biological internal fixation: choosing a new balance between stability and biology. J Bone Joint Surg Br.; 84(8):1093-110.

- SAS (2012).Statistical Analysis System Users Guide .Statistical Version $9^{\text {th }}$ ed SAS. Inst inc. Cary. N.C. USA

- Singh Ajai, AS.; Mahdi, AA.; and Srivastava, RN. (2013). Evaluation of serum alkaline phosphatase as a biomarker of healing process progression of simple diaphyseal fractures in adult patients. Int Res J Biol Sci 2: 40-43.

- Stiftler, Ks.(2004). Internal fracture fixation,clin Tech Small Anim Pract. Aug: 19(3):105-13.

- Zimmermann, G.; Henle, p.; Küsswetter, M.; Moghaddam, A.;Wentzensen, A.; Richter, W.; and Weiss, S.(2005).TGF- $\beta 1$ as a marker of delayed fracture healing. Bone 36: 779-785. 